\title{
DISCURSO NO PALÁCIO DOS BANDEIRANTES POR OCASIÃO DA SESSÃO SOLENE DO CONSELHO UNIVERSITÁRIO NA COMEMORAÇÃO DOS 70 ANOS DA USP
}

\author{
Antonio Junqueira de Azevedo \\ Professor Titular do Departamento de Direito \\ Civil da Faculdade de Direito da \\ Universidade de São Paulo
}

Exmo. Sr. Dr. Geraldo Alckmin, Governador do Estado de São Paulo.

Exmo. Sr. Deputado Sidney Beraldo, Presidente da Assembléia Legislativa do Estado de São Paulo.

Magnífico Reitor, Prof. Adolpho José Melfi, a quem agradeço a honra de me dar a palavra nesta cerimonia - certamente numa deferência especial à Faculdade de Direito, a mais antiga das unidades da USP.

Exmo. Sr. João Carlos de Souza Meirelles - secretário de Estado da Ciência, Tecnologia, Desenvolvimento Econômico e Turismo.

Exma. Sra. Dra. Cláudia Costin, secretária de Estado da Cultura.

Exmo. Sr. Rui Mesquita, em cuja pessoa reverencio todos fundadores da USP, em especial, Armando de Salles Oliveira (que assinou do Dec. n. 6.283, de 25 de janeiro de 1934) e Julio de Mesquita Filho, que tanto lutou pela sua criação.

Magnífico ex-reitor Prof. Miguel Reale, em que saúdo os demais ex-reitores presentes. Demais autoridades,

Prezados companheiros de USP, minhas senhoras e meus senhores,

Tratando-se de uma universidade, reunida em sessão solene, em pleno Palácio do Governo, diante das autoridade, a retórica oferece ao orador a tentação de hipostasiar o Conhecimento e a Política, isto é, de lhes das substância personalizadas e dizer "cá estamos, o Saber diante do Poder"

Mas, aos 70 anos, a prudência da idade e, ainda, a noção dessa terceira grande presença, que é a do público em geral, impedem os excessos da presunção humana: afinal, nem o saber é tão definitivo - estamos numa universidade - nem o poder é tão permanente - estamos numa República. 
Na relatividade das coisas, o próprio povo, aqui chamado como espectador e ouvinte mas, na verdade, o grande produtor dos bens e serviços que consumimos, também não se deve deixar levar pelo orgulho na proclamação constitucional de sua soberania; não-somente é ele limitado em suas decisões pelos direitos fundamentais como também as atuais preocupações com o meio ambiente (em cujas pesquisas, vale dizer desde logo, a USP tem-se dedicado com intensidade) devem levá-lo a se conscientizar de suas responsabilidades para com as gerações futuras, e, vejam todos, essas gerações não têm representantes nas assembléias e parlamentos. É o que salienta Hans Jonas em livro sobre a nova ética, "Le principe responsabilité" (na tradução francesa).

Georges Dumizil atribuía aos povos indo-europeus, ora pela concepção de três classes, a dos dirigentes, a dos intelectuais e a dos produtores a nobreza, o clero e o terceiro estado da Idade Média - uma visão triádica do mundo e da sociedade. Ao falar, agora, em poder, saber e produção três funções sociais - . não sei se estou a concretizar uma inexorável forma mentis mas, convém, na verdade, nesse momento de avaliação, raciocinar, ainda que superficialmente, sobre o papel, ou a função, da USP na sociedade. É o que faremos.

Esse tema se confunde com a chamada "democratização da universidade" Sem pretensão de expor verdades definitivas, parece-me que "democratização" é a idéia que aqui se presta a exame sob dois aspectos diferentes: a democratização interna e a externa.

A primeira, por sua vez, abrange tanto o relacionamento professor/aluno em sala de aula quanto a escolha dos dirigentes. Parece-me, senhor Governador e senhor Presidente da Assembléia, que a USP, nessas questões, soube caminharmos para uma igualdade entre professor e aluno, a ponto de fazer desaparecer a auctoritas inerente à função de ensinar, nem mantivemos um método doutoral, no mal sentido, em que nenhuma palavra é dada ao aluno, até porque não é função do professor universitário ser um mero repetidor de conhecimentos adquiridos. Por outro lado, quanto aos cargos de direção, não caímos também na tentação de sufrágio universal. Nesta questão, como na anterior, o princípio, na USP, a dizer verdade, é antes republicano que propriamente democrático: respeita-se a auctoritas dos professor, há eleição dos dirigentes, mandatos temporários, rodízio nos cargos.

Talvez, porém, o que mais importa para o Estado e a sociedade seja o aspecto externo da democratização, a função social no sentido próprio. Ora, também sob esse aspecto, o tema se desdobra em dois: o acaso à universidade e o da produção acadêmica, - que melhor se diria o do resultado final das atividades universitárias. 
No Decreto de fundação (Dec. n. 6.283 de 25 de janeiro de 1934_estava determinado: “Art. $2^{\circ}$ : São fins da Universidade: a) promover, pela pesquisa, o progresso da ciência; b) transmitir pelo ensino, conhecimentos que enriqueçam ou desenvolvam o espírito, ou sejam úteis á vida; c) formar especialistas em todos os ramos de cultura, e técnica ou artística; d) realizar a obra social de vulgarização das ciências, das letras e das artes, por meio de cursos sintéticos, conferencias, palestras, difusão pelo rádio, filmes científicos e congeneres.

Esses fins; ensino, pesquisa e prestação de serviço à comunidade, repetidos com palavras semelhantes nos estatutos que se sucederam, têm sido amplamente cumpridos. Os "institutos oficiais" (previstos no art. $3^{\circ}$ do Decreto) eram, em 1934, dez: a) quatro já existentes: Faculdade de Direito, Faculdade de Medicina, Escola Politécnica e Escola Superior de Agricultura; b) três, remodelados: Instituto de Educação , Faculdade Farmácia e Odontologia e Escola de Medicina Veterinária; e c) três, a serem criados: Instituto de Ciências Econômicas e Comerciais, Escola de Belas Artes e, finalmente, a faculdade de Filosofia, Ciências e Letras, que foi, sem dúvida, a menina dos olhos do fundação da USP - basta ler o cuidado com que foi prevista no Decreto de fundação. São, hoje, as faculdades, escolas e institutos, em número de 36.

A quantidade de aluno tem aumentado constantemente - são hoje mas de 70.000 - merecendo referência especial o esforço para aumento de vagas nos cursos noturnos e, nos últimos 30 anos a enorme evolução da pós-graduação. Sobre a pesquisa, a difusão de seus resultados e a prestação de serviços, tendo em vista o provável fornecimento de dados mais concretos, na manifestação do Magnífico Reitor, limitome a repetir o dado dos jornais de que $25 \%$ da ciência brasileira é feita na USP. Parecem, assim, sem triunfoalismo, razoavelmente cumpridas as finalidade de sua fundação.

Entre parêntesis, considerando o que lemos em jornais destes dias, vale dizer que a afirmação de alguns autores de que os traços iniciais da USP "foram moldados pela reação da elite local às derrotas da Revolução de 30 e 32" (Carlos Lessa, in F.S.P. de 23 de jan. de 2004) ou que os fundadores "tinham, noção clara do que queriam: formar uma elite que repusesse São Paulo, depois da derrota da Revolução de 32, em posição hegemônica" (FHC in F.S.P. de 23/1/2004), não expressam a verdade, já que o movimento pela universidade vinha de muito antes. Transcreveremos Fernando de Azevedo, em textos esclarecedores ("Ensaios Paulistas", Ed. Anhembi, São Paulo, 1958, pg. 216 e ss.) "antes dessa iniciativa do govêrno provisório em 1931, e mesmo antes da criação da Universidade de Minas Gerais, em 1927, e da do Rio de Janeiro em 1920, já nos batiamos em São Paulo por uma Universidade que tivesse como eixo 
do gravitação de todo o sistenta, una Faculdade destinada a ser um centro de cultura filosófica e literárias e foco poderoso de atividades cientificas" E mais adiante: "O que, pois, se pretendeu promover, com a criação da Universidade, era importante mudança de orientação, uma pequena revolução intelectual. Parecia-nos que já podia ser aspiração oportuna a que antes se afigurava a todos projetos ambicioso. Mas seria preciso ou ao menos conveniente, para erguê-la sobre sólidos alicerces, proceder a uma larga sondagem, em debate público, e preparar a opinião, ainda totalmente desinteressada do problema universitário como, de modo geral, que questões referentes à educação. Daí o inquérito que, para "O Estado de São Paulo" me solicitou em 1926 Júlio de Mesquita Filho, em que, por sua devoção os progressos da cultura e pela clara inteligência do papel das Universidades no conjunto das instituições democráticas, encontrava a idéia universitária un dos lidadores mas tenazes de sua propaganda e um de seus mais antigos e fiéis propugnadores" No mesmo sentido, Ernesto de Souza Campos, no cuidadoso livro sobre a histórica da USP, escrita por ocasião do $4^{\circ}$ Centenário de São Paulo (1954). Vale lembrar, finalmente, que, em 1927, os próprios estudantes da Faculdade de Direito representaram ao Congresso Nacional, pedindo a criação de uma universidade paulista; o texto tem a assinatura de J.B. de Arruda Sampaio, Oscar Pedroso Horta, Mercado Jr., Affonso Augusto Netto, José de Aguiar Pupo e Soares Lara.

Por essas citações, vê-se bem, pois, que o que lemos nesses dias, sobre a USP como "revanche" de 32, não expressa a verdade, ou toda a verdade.

Se o saldo da produção acadêmica é positivo, passemos, finalmente, à questão do acesso à Universidade. É tema aberto, ainda não definitivamente resolvido, eis que estamos todos, uspianos, cientes, nesse ponto, de uma evolução indesejável que consiste, de uns quinze anos para cá, no aumento constante de ingressantes promovidos de escolas particulares, e não, de escolas públicas. Isto não contribui para melhor distribuição de renda. Aqui se apresenta também a polêmica questão das quotas para negros. Respeito as opiniões contrárias mas há mais de dez anos, quando o tema ainda não propunha tão intensamente, já defendia eu a política de quotas. Sei que o assunto é contravertido mas considerando que os argumentos se repetem de lado a lado, não posso deixar passar a oportunidade de me referir a um ponto, do qual pouco se fala, e é este: a maior presença de alunos negros em sala de aula é um chamado eloqüente da atenção de professores e estudantes para o Brasil real. Esse apelo à concretude é pedagógico, visa o futuro, é capaz de levar à modificação de currículos $\mathrm{c}$ idéias, abrindo caminho para um Brasil melhor. 
Finalmente, dignas autoridades, uma palavra somente sobre as relações entre a Universidade e o Estado: minha impressão, após mais de 36 anos de Universidade, é a de que essas relações nos últimos quinze anos, melhoraram muito. Penso que se pode dizer de forma otimista que essas relações são, hoje, como devem ser: a Universidade, diante do Governo, é autônoma mas age com harmonia. Assim, para finalizar, se me perguntassem como devem ser essas relações, ousaria repetir as palavras que, em outro contexto, usou o Papa Clemente XIII, "sint ut sunt", isto é, "que sejam conıo já são"

Muito obrigado!!

São Paulo, 25 de janeiro de 2004. 


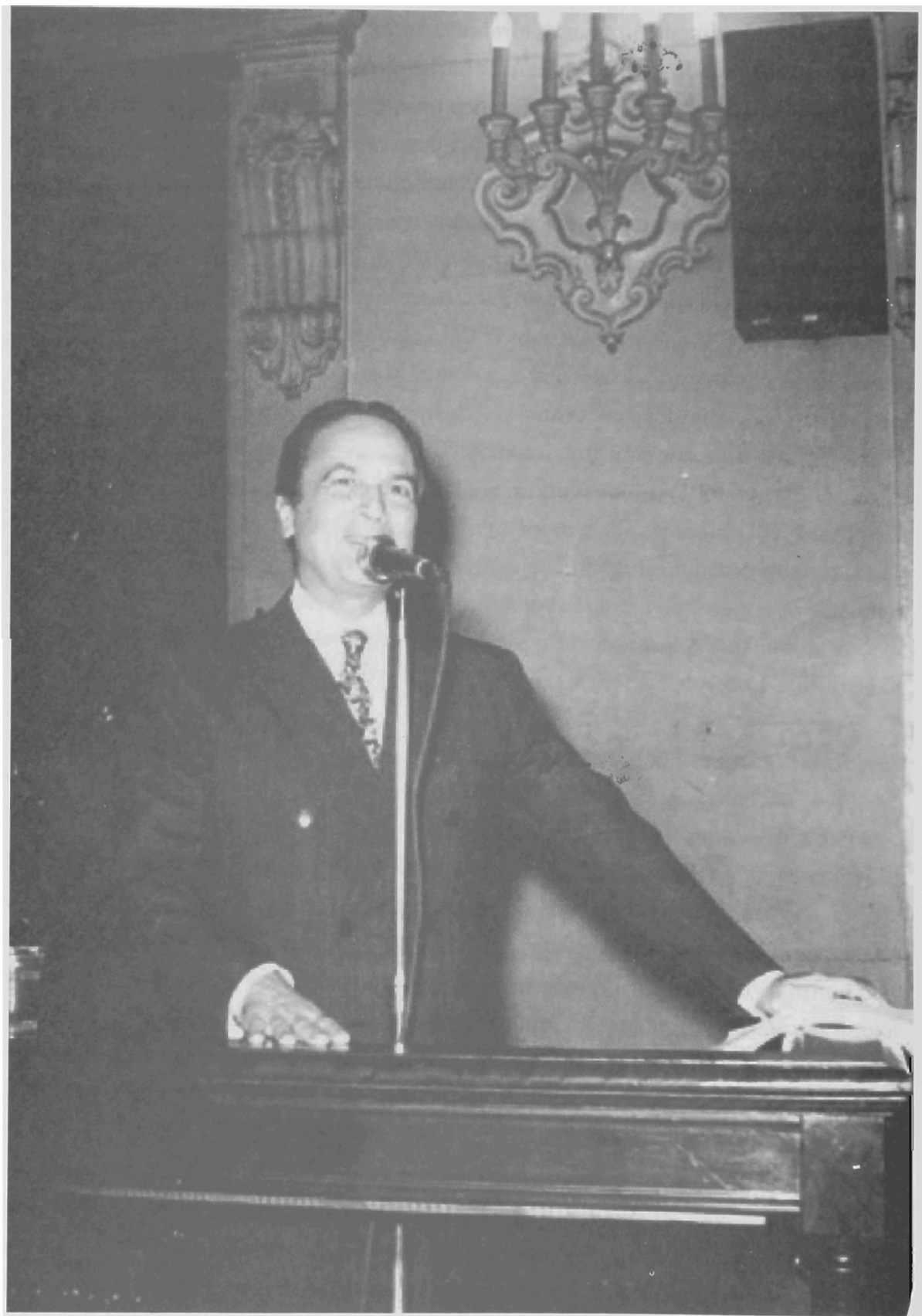

Professor Titular Antonio Junqueira de Azevedo . 